Anuario Latinoamericano Ciencias Políticas

y Relaciones Internacionales

vol. 3, 2016

pp. $71-87$

DOI: 10.17951/al.2016.3.71

\section{La actividad misionera de unas misiones de fe entre los grupos indígenas de la región amazónica y los intereses políticos de los gobiernos latinoamericanos}

\section{The missionary activity of some faith missions among indigenous groups in the Amazon region and the political interests of Latin American governments}

\author{
Magdalena Krysińska-Kałużna ${ }^{1}$ \\ CENTRO DE ESTUDIOS LATINOAMRICANOS \\ UNIVERSIDAD DE VARSOVIA, POLONIA \\ $\triangle$ m.krysinska-ka@uw.edu.pl
}

\section{RESUMEN}

En América Latina, la vinculación entre la política y los intereses económicos específicos se concentró a menudo - a causa de los recursos naturales - en las zonas habitadas por los indígenas donde trabajaban los misioneros. El artículo muestra la conexión entre los efectos de las acciones de los misioneros del Instituto Lingüístico de Verano y la Misión Nuevas Tribus y los intereses políticos de los gobiernos latinoamericanos y empresas estadounidenses. Estos procesos se ilustran en los acontecimientos que tuvieron lugar en la Amazonía ecuatoriana, en los territorios de los Huaorani y entre los Aché en Paraguay.

PALABRAS CLAVE: misioneros, indígenas, Huaorani, Aché, intereses políticos.

\begin{abstract}
In Latin America, the interrelations between politics and specific economic interests are often concentrated - due to the presence of natural resources - in areas inhabited by indigenous peoples where missionaries used to operate. The article shows the correlation between the effects of missionary work of the Summer Institute of Linguistics and the New Tribes Mission and the political interests of Latin American

1 Antropóloga interesada en la dimensión práctica de investigación (Antropología en acción) especialmente en el contexto de los pueblos indígenas de América Latina, problemas teóricos relacionados con el dominio de la cultura y la transformación de la cultura dominada, la relación entre las leyes escritas y el derecho consuetudinario, derechos humanos en el contexto de relativismo cultural, el conflicto de culturas, el multiculturalismo, el cambio cultural, discriminación, la situación de las minorías culturales, étnicas y sociales.
\end{abstract}


Dossier América Latina: política y religión governments and US companies. These processes are illustrated by the events that took place in the Ecuadorian Amazon, in the territory of the Huarani and in Paraguay among the Aché.

KEYWORDS: missionaries, indigenous peoples, Huaorani, Aché, political interests.

Las relaciones entre la religión y política fueron un factor importante para el destino de los grupos indígenas con los cuales las sociedades nacionales establecieron contactos en la Amazonía durante la segunda mitad del siglo XX. En América Latina, la vinculación entre la política y los intereses económicos específicos se concentró a menudo - por causa de los recursos naturales - en las zonas habitadas por los indígenas. En tal situación, las influencias religiosas estaban siendo utilizadas con fines económicos y políticos.

En América del Sur, los gobiernos que trataban favorablemente a los Estados Unidos facilitaron a las organizaciones protestantes realizar actividades misioneras, asumiendo que estas instituciones serían útiles en la lucha contra la influencia del comunismo y la teología de la liberación. Estas organizaciones incluyen, entre otras, al Instituto Lingüístico de Verano (ILV), el cual tiene interés sobre todo en las lenguas amenazadas, y la Misión Nuevas Tribus $(\mathrm{MNT})^{2}$ cuyo énfasis estaba puesto en los grupos aislados. Ambas son "misiónes de fe" $\mathrm{fe}^{\text {y }}$ ambas realizaban un papel muy importante en la conversión de los indígenas al protestantismo y, al mismo tiempo, contribuyeron al cambio cultural importante entre los grupos con los cuales mantenían contacto ( $c f$ :: Hvalkof, Aaby 1981; Bottasso 1990).

Los cambios culturales y las relaciones entre grupos misioneros y grupos indígenas se pueden analizar en el contexto de la dominación cultural. Esta categoría significa un tipo de relación social, que puede ser descrita como "ejercer presión" por los representantes de la cultura de una determinada comunidad (generalmente más grande) sobre los representantes de otras culturas (por lo general, minoritarias). El objetivo de esta acción es la voluntad de controlar, absorber o aislar a estas culturas (Mucha 1999: 26). Ligeramente diferente define esta noción James Fenelon. En su opinión, la dominación cultural es una “acción, estructura o ideología derivada de los grupos culturales dominantes o de los Estados-nación (nation-states), que utiliza cualquier compulsión, represión directa o eliminación estratégica de las prácticas culturales de los grupos culturales dominados" (Fenelon 1998: 37). La dominación cultural es, por

2 Instituto Lingüístico de Verano (ILV) - inicialmente llamado en inglés Summer Institute of Linguistics (SIL) - ahora se llama oficialmente SIL International. El nombre inglés de la organización Misión Nuevas Tribus es New Tribes Mission (NTM).

3 El término "misión de fe" es empleado para referirse a las organizaciones misioneras cuyos empleados no tienen un sueldo, pero se financian mediante sus iglesias, amigos y hermanos de fe. A menudo, uno de los principios básicos de este tipo de misiones es no pedir apoyo financiero. Los misioneros no comunican sus necesidades cuando se les pregunta. "La fe" se refiere a la creencia en la provisión de Dios, destinada a satisfacer todas las necesidades. 
consiguiente, la imposición de un patrón a la cultura "más débil” de la cual se requiere una aceptación de la visión extranjera del mundo, valores y normas del grupo más fuerte (Fenelon 1998: 25-87). Un caso especial, o un aspecto de este fenómeno, es imponer a los otros sus propias categorías conceptuales (Said 1991).

El problema de este complejo modelo cultural, la cultura dominante, puede ser visto en el contexto de la dominación política, en particular, teniendo en cuenta los instrumentos de dominación como las relaciones socio-históricas, que se revelan en el nivel institucional (por ejemplo: Fenelon 1998). Este enfoque está relacionado con la idea de la escuela de Frankfurt, pero también con una visión del poder como la conceptualiza Steven Lukes en su "Poder: un enfoque radical" ("Power: A Radical View"). De acuerdo con este autor, la visión de poder unidimensional - propuesta, por ejemplo, por Robert Dahl, Raymond E. Wolfinger y Nelson W. Polsby - y bidimensional - según Peter Bachrach o Morton S. Baratz - son inadecuadas. Sólo la visión tridimensional puede explicar este fenómeno (Lukes 1997).

La visión unidimensional del poder pone énfasis en el comportamiento de la toma de decisiones sobre cuestiones donde existe un conflicto de intereses subjetivos observables. Estas decisiones son tomadas como una expresión de las preferencias políticas y se revelan en la participación en el proceso político (Lukes 1997: 299). El problema clave para Bachrach y Baratz, que representan visión bidimensional, es como identificar las cuestiones políticas que no se actualizan. Insisten en el conflicto real observable que se manifiesta o está latente (Lukes 1997: 302). En la opinión de Lukes, el poder es un proceso de dominación, el proceso que asegura la obediencia de los dominados. Este concepto sirve para analizar cómo los poderosos hacen que la obediencia sea voluntaria (a pesar de que puede coexistir con la resistencia), teniendo en cuenta la estructura y el individuo. “ ¿No es lo más satánico - dice Lukes - y la mejor forma de ejercer autoridad, si no permitir, de ninguna manera, que la gente sienta el descontento, formar sus preferencias y la manera de conocer y percibir la realidad? ¿ Si esto sirve para que acepten su papel en el orden existente, o para que lo perciban como una condición necesaria e inmutable, o para que lo aprecien como un capricho divino beneficioso para todos ellos? La suposición de que la falta de insatisfacción es igual al verdadero acuerdo se reduce a la exclusión, por definición, de la posibilidad de que el consentimiento sea falso o manipulado" (Lukes 1997: 304).

Hablando de la dominación cultural y de la visión tridimensional de poder seguimos también a Pierre Bourdieu y a su concepto de violencia simbólica y estudios del proceso de poder y de su internalización. Para el sociólogo francés, dominación cultural es a menudo el sinónimo de la violencia simbólica y la imposición de significados como legítimos "y al mismo tiempo oculta las fuerzas subyacentes” (Bourdieu, Passeron 1990: 60). Bourdieu asume que existe una correspondencia entre la estructura social (incluyendo la división del mundo entre dominantes y dominados) y las estructuras de pensamiento: la presión de la realidad externa imprenta al mente las "disposiciones perma-
La actividad misionera de unas misiones de fe entre los grupos indígenas de la región amazónica y los intereses políticos de los gobiernos latinoamericanos Magdalena Krysińska-Kałużna 
Dossier América Latina: política y religión nentes". El sistema simbólico no es sólo una herramienta de conocimiento, sino que también se convierte en una herramienta de dominación, que permite la integración de la sociedad en torno a un orden impuesto arbitrariamente (Wacquant 2001: 16-18). Para entenderlo mejor, es de mayor utilidad otro concepto de Bourdieu: el concepto de habitus.

La formación de un habitus es la ejecución de las estructuras externas del entorno. Habitus se convierte en la matriz de la percepción, pensamiento y acción (Bourdieu 2004: 45). "Adquiridos por la experiencia, los esquemas cognitivos organizan todo el proceso de la percepción y definen una visión subjetiva del mundo" (Jacyno 1997: 28). Habitus conformado en la cultura tradicional puede ser inapropiado para entender el mundo en la situación de contacto cultural - no puede ayudar en un juego al que "no sabe" como jugar. Por lo tanto, a menudo los dominados "mismos" se sitúan fuera de la sociedad. Según Bourdieu, disposiciones que les inducen a eso son resultados de la dominación internalizada (Jacyno 1997: 25).

El reconocimiento de la dominación es siempre a través de la comprensión y el conocimiento - las condiciones en las que se forman los patrones de percepción y disposición forzan a los dominados a adoptar el punto de vista de los grupos dominantes (Bourdieu 2004: 53-55). En la aceptación no reconocida e inconsciente de las cosas está basada la violencia simbólica, que - según Bourdieu - puede ser mucho más eficaz que la violencia política y policial (Bourdieu, Wacquant 2001: 160-163). Es la forma de violencia que afecta al sujeto con su propia participación.

Pienso que los gobiernos latinoamericanos usaron los misioneros como agentes del contacto, miembros de la cultura dominante, con la intención de dominar los grupos recién contactados por la violencia simbólica. Renunciaron al uso de la violencia definida sólo por la visión unidimensional y ejercer el poder en una manera "simple". Las acciones de los misioneros se pueden ver como el uso del poder en las dimensiones propuestas en la visión tridimensional, tal como la entiende Lukes. El uso de la violencia física no era entonces excluido, pero no era lo más importante y más suficiente.

En el artículo pretendo mostrar cómo las acciones de SIL y NTM conectaban actividad misionera con los intereses políticos de los gobiernos latinoamericanos y las empresas estadounidenses. Una ilustración de estos procesos son los acontecimientos que tuvieron lugar en Paraguay y en la Amazonía ecuatoriana. Mi análisis es resultado de un estudio bibliográfico y estudio de campo entre los indígenas Huaorani de Ecuador llevado a cabo en 1991.

\section{Misión Nuevas Tribus y los Aché}

Después del comienzo de la guerra civil en China en 1927, y especialmente después de la invasión y ocupación de Manchuria por los japoneses, cerca de 5 mil misioneros tenían que salir de este país. América Latina fue escogida 
como un nuevo campo de misión en la Conferencia de Misiones en Tambaram, cerca de Madrás, en 1938. Entre las misiones que aparecen en América Latina es la Misión Nuevas Tribus (MNT) (Rohr 1997: 106). La MTN fue una parte de la "tercera ola" de los misioneros en América Latina, creada por misiones de fe fundamentalistas. La primera y segunda ola, del siglo XIX y principios del XX, la formaban las iglesias de los inmigrantes europeos, por ejemplo, los luteranos alemanes de Brasil y algunos de los cultos principales de los Estados Unidos (Stoll 1993).

La MNT - que hoy tiene su sede principal en Sanford, Florida - fue fundada por Paul Fleming de Los Angeles, en 1942. El mismo año, la organización envió su primer grupo a Bolivia. En 1943, la MNT comenzó a publicar la revista „Gold Brown”. Con el tiempo los misioneros establecieron contactos con varios grupos indígenas, entre otros con los Makú del Alto Río Negro-Vaupés en Colombia o con los Zo’e, Waiãpi y Wari’ en Brasil ( $c f$. Tilkin Gallois, Benzi Grupioni 1995). En Paraguay, la MNT trabajó con los Ayoreos y los Aché.

Los Aché es un grupo indígena de la región oriental de Paraguay. Tradicionalmente eran nómadas y se dedicaban a la cacería y recolección de frutos, miel y raíces silvestres. A finales de los años 60 del siglo XX, durante la dictadura militar del general Alfredo Stroessner, se decidió que el sector agroganadero y otras empresas necesitaban los territorios de los Aché y que la parte del grupo que seguía sin contacto con la sociedad nacional debía, ser „pacificada”. Entonces, entre 1970 y 1978, se emprende la salida forzada del bosque de los últimos grupos de los Aché. ${ }^{4}$ La práctica de organizar las cacerías de esa gente era bastante común desde los primeros contactos con los blancos. La sedentarización forzada de los indígenas estaba conectada con asesinatos y esclavitud de los Aché vendidos como mano de obra (Parellada, Beldi de Alcántara (eds.) 2008). Uno de los más poderosos comerciantes de los esclavos indígenas fue un terrateniente local, Manuel Jesús Pereira, quien trabajaba para el Departamento de Asuntos Indígenas (DAI) de Paraguay. El director del Departamento visitaba la „reserva” creada por Pereira en su granja y él mismo vendió los Achés como esclavos (Survival International, 2014). En 1968, el Estado creó una reserva llamada "Colonia Nacional AchéGuayakí" de Cerro Moroti. Pereira fue el administrador de la Colonia hasta septiembre de 1972. Los que sobrevivieron las prácticas de correrías fueron colocados en la reserva, la cual luego fue administrada por los misioneros de la Misión Nuevas Tribus.

Lo que sucedía a los Aché fue denunciado internacionalmente en 1973 por un antropólogo alemán Mark Münzel en un informe „El pueblo aché: Genocidio en Paraguay” (Münzel 2008a) publicado primero por la organi-

4 Al final de los años 60 y comienzos de los 70 existían todavía cinco zonas donde vivían los Aché aislados (Santa Cruz 2012: 16).
La actividad misionera de unas misiones de fe entre los grupos indígenas de la región amazónica y los intereses políticos de los gobiernos latinoamericanos Magdalena Krysińska-Kałużna 
Dossier América Latina: política y religión zación danesa IWGIA. ${ }^{5}$ Ese documento y también el otro „Los aché: El genocidio continúa en Paraguay" (Münzel 2008b), del mismo autor, son unas de las evidencias muy fuertes de lo que ahora está clasificado como el genocidio o etnocidio. En el año 2008, la Coordinadora de Derechos Humanos (Codehupy), junto con la Comisión de Verdad y Justicia en Paraguay, llevó a cabo una investigación de las violaciones de derechos humanos que tuvieron lugar durante la época de la dictadura de Alfredo Stroessner contra los pueblos indígenas en Paraguay. Según el informe de la Codehupy, los Aché, Ayoreo, Paî Tavyterâ, Toba Maskoy, Angaité, Enxet Sur, Sanapaná y Avá Guaraní, entre otros, son los grupos cuyos derechos fundamentales fueron violados (Comisión Verdad y Justicia 2008: 1). La Comisión priorizó las entrevistas en terreno con los indígenas Aché „cuyo pueblo, padeció de matanzas grupales, robos y desaparición de niños y niñas; traslado forzoso, violación de mujeres; sometimientos de niños, niñas y preadolescentes al sistema de 'criaditos/as' con familias paraguayas; y la campaña de misionalización forzosa [énfasis - MKK] con creencias ajenas a sus pautas culturales por parte de misioneros extranjeros fundamentalistas" (Comisión Verdad y Justicia 2008: 2).

Esa „misionalización forzosa” mencionada por Codehupy parece estar en línea con los intereses del gobierno paraguayo de los tiempos de la dictadura. Como escribe Münzel, los representantes de esa institución („voceros del gobierno paraguayo”) enfantizaban que no querían preservar las culturas indígenas „sino, por el contrario, están a favor de 'asimilarlos a nuestras costumbres” (Münzel 2008b: 114). Los misioneros, en sus esfuerzos de contactar los grupos aislados, sedentarizarlos y bautizarlos, usaron la gente llamada "señuelos". Fueron los Aché capturados hacía años y usados para sacar a sus hermanos del monte. En el relato de Lorenzo, un señuelo, leemos:

„A mí Pichín me cambió por una vaca al Sr. Vega que me llevó a su establecimiento ubicado en la zona de Enramadita donde tuve que trabajar muy duro en la chacra y muchas veces fui castigado por mis patrones. Después de muchos años actué de guía para el señor Fosterwol, misionero norteamericano, para contactar con los Aché que aún vivían en el monte, temía que mis hermanos indígenas murieran todos en el monte, porque a menudo los paraguayos y militares entraban a cazar niños y matar a los adultos. Por esa razón me uní a los misioneros para contactar con los Aché, y le pedí que salieran, caso contrario, corrían el riesgo de morir todos. Les dije que los misioneros son buenas personas y que no les faltaría nada" (Servín 2008: 158).

En Paraguay, la MNT actuó en convivencia con el dictador Stroessner. La política de conversión y los campamentos de asentamiento encajaban muy bien con sus planes para la apertura de la selva para los intereses mineros y madereros ( $c f$. Servín 2008). Los misioneros, usando los señuelos, iniciaron

5 Esta situación trágica de los Aché fue luego denunciada a la Comisión Interamericana de Derechos Humanos (CIDH). Testimonios sobre la situación de los Aché publicaron también otros antropólogos como Miguel Chase Sardi, David Maybury Lewis o Kim Hill. 
el contacto con los Aché y luego les desplazaron a la reserva. Ahí, les dijeron que tenían que dejar su forma de vida. Mientras que sucedía eso, la tierra de los indígenas fue vendida. René D. Harder Horst, quien proviene del ámbito menonita, analizando las relaciones entre la población indígena, el régimen de Stroessner y las misiones religiosas, dice que la agenda indigenista era ambigua suficientemente para permitir acomodar objetivos cambiantes de las autoridades. „Los planes de Stroessner para los pueblos indígenas evolucionaron con el régimen desde una política inicial de integración común en Latinoamérica durante el período indigenista inicial a otra de exclusión diseñada a perpetrar la desaparición de los nativos a toda costa" (Harder Horst 2011: s/p). Según el mismo autor, la jerarquía católica en ese tiempo chocaba con la dictadura, reduciendo la cooperación con el DAI, y los misioneros protestantes la fortalecieron. Esa cooperación era muy beneficiosa para el gobierno porque los misioneros financiaban sus propios proyectos. „Infanzón ${ }^{6}$ igualmente autorizó a misiones protestantes nuevas a iniciar proselitismo en asentamientos indígenas" (id.). Cooperación entre los misioneros protestantes y DAI vino „facilitando el trabajo de este departamento" (id.).

En 1974, el IWGIA publicó el segundo informe de Mark Münzel titulado „Los aché: El genocidio continúa en Paraguay”. Münzel acusa a los misioneros de practicar las cacerías humanas. „El pastor trató nuevamente de traer a sus ovejas de regreso a casa. Es difícil conocer qué medios usó para esto. La carta del 18 de julio de 1973 declara que los misioneros de 'Las Nuevas Tribus' están ahora cazando, (mediante vehículos motorizados) Guayakí (Aché) en la región de Igatimi, a fin de reintegrarlos a la colonia. (...) El 16 y 17 de septiembre de 1973, una banda de 46 indígenas achés fue traida a la colonia en un camión, 'por designio de Dios' y con la ayuda del Departamento de Asuntos Indígenas del Ministerio de Defensa Nacional y de las autoridades policiales locales" (2008: 118-119).

Según la opinión de Harder Horst, informes originales de Münzel - también cuando escribió sobre las cacerías humanas llevadas a cabo desde la reserva - fueron, por lo menos, exagerados (Harder Horst 2011; cf. también e.g.: Harder Horst 2000). Pero la misma practica de las cacerías humanas está descrita también por Norman Lewis quien visitó la colonia (o la reserva) de los Aché, dirigida por los misioneros de la Misión Nuevas Tribus, en el año 1974 (Lewis 1988).

Los misioneros declararon que su propósito es cooperar en el desarrollo del país y una parte de este declarado desarrollo fue la integración de los grupos indígenas. Este tipo de la cooperación beneficiaba tanto a las agencias religiosas como al gobierno. La integración que practicaban los misioneros fue de hecho la aculturación forzosa, la cual ahora se puede llamar etnocida. No fue solo la evangelización, pero también, entre otros, la prohibición de caza, de ri-

${ }^{6}$ Coronel Tristán Infanzón, el director del Departamento de Asuntos Indígenas de Ministerio de Defensa.
La actividad misionera de unas misiones de fe entre los grupos indígenas de la región amazónica y los intereses políticos de los gobiernos latinoamericanos Magdalena Krysińska-Kałużna 
Dossier América Latina: política y religión tos tradicionales y la destrucción de los liderazgos tradicionales (Servín, 2008, p. 156; Mesa memoria histórica y archivos..., p. 3).

Seguramente, como el señuelo Lorenzo dice en su relato, seguir a los misioneros fue para los Aché la mejor o la única solución, si no querían morir de las manos de „paraguayos o militares”. Pero, por otro lado, hay que recordar que este proyecto gobernamental de „salvar” a los indígenas, llevado a cabo entre 1970 y 1978, resultó con aniquilación de cerca del 40\% de la población de los Aché norteños por las epidemias y también con el robo de sus tierras ancestrales (Servín 2008). La parte de este proyecto constituyeron los misioneros.

\section{El Instituto Lingüístico de Verano y los Huaorani}

El Instituto Lingüístico de Verano (ILV) fue fundado por William Cameron Townsend en 1934 como la parte de la organización misionera llamada Wycliffe Bible Translators (WBT) (en honor a John Wycliffe - teólogo inglés del siglo XIV, declarado hereje por su iglesia y primer traductor de la Biblia al inglés). El ILV iba a cumplir objetivos científicos.

El primer viaje de Townsend a México, en 1933, como parte de trabajo de Pioneer Mission Agency (antes él trabajó con los indígenas en Guatemala), fue tan desalentador que, después de su regreso, decidió adoptar una estrategia que influyó toda futura actividad misionera del ILV/WBT. El movimiento social en México era en ese tiempo anti-estadounidense y anti-eclesiástico. Townsend decidió que los misioneros debían ir a este país como lingüistas o traductores sin decir nada que eran misioneros y que debían afirmar que las donaciones a la organización provenían de los "individuos" de los EE.UU. En México debían presentarse como los seguidores de la Revolución Mexicana (Stoll 1981a).

Esta muy pragmática actitud se convirtió en un elemento importante en el funcionamiento de la organización y más tarde fue a menudo la causa de la crítica dirigida contra el ILV/WBT, tanto por parte de los antropólogos [Hvalkof, Aaby (eds.) 1981] como por los periodistas de América Latina, que acusaron a ILV que los objetivos de sus operaciones en los países latinoamericanos son muy diferentes de los declarados oficialmente (Pérez, Robinson 1983). Por esta razón el ILV fue criticado también por los mismos misioneros (Tucker 1995).

David Stoll distingue tres fases en el funcionamiento del ILV:

1. Desde 1945 hasta 1953. En ese tiempo, el ILV funcionó como un frente virtual para WBT;

2. En la segunda fase el ILV y WBT se presentan como organizaciones "hermanas".

3. Cuando finalmente resultó que científicos del ILV pertenecen a una organización misionera que tiene por objeto la predicación del cristianismo, se caracteriza por enfatizar la compatibilidad de la ciencia y la religión, 
la relatividad del sistema de creencias y el respeto para las culturas indígenas (Stoll 1981: 24 ).

En América Latina, decidieron colaborar con el ILV los gobiernos de México, Perú, Ecuador, Guatemala, Honduras, Bolivia, Brasil, Colombia, Panamá, Surinam, Chile y Venezuela. ${ }^{7}$ En la mayoría de los casos, esta cooperación se basaba en la firma de contratos con los ministerios de educación, que encargaron al ILV realizar la educación bilingüe entre la población indígena.

El Instituto - que estaba comprometido con el objetivo de traducir la Biblia a todos los idiomas del mundo - quiso trabajar con los grupos indígenas que tenían contacto con la sociedad nacional desde mucho tiempo atrás, pero también establecer contactos con los grupos aislados. La pacificación de los indígenas estaba en el interés de los gobiernos que, como en el caso de la Misión Nuevas Tribus, podían esperar rápida integración de los pueblos indígenas a las sociedades nacionales, sin tener que pagar los costos de estas operaciones. El ILV, obedeciendo el principio "al César lo que es del César", nunca oficialmente resistía a la política del gobierno (aunque los misioneros individuales trataban de ayudar a las organizaciones o grupos indígenas en sus esfuerzos para mejorar su posición con respecto a las autoridades ${ }^{8}, c f$. Stoll 1981b). Había una alianza peculiar entre el Instituto, el cual identificaba Satanás con el comunismo, y los gobiernos conservadores. "Para los misioneros del ILV - escriben Søren Hvalkof y Peter Aaby - Satanás no es sólo un concepto abstracto que abarca las tendencias humanas malignas. Él es, en cambio, una verdadera encarnación social cuya manifestación más clara es el comunismo. Teniendo en cuenta el origen social de los miembros del ILV, esta identificación de Satanás, con el comunismo parece lógica. Del mismo modo, existe una tendencia igualmente natural de Dios de ser transformado en un estadounidense" (1981: 11). ${ }^{9}$

Entre las críticas del ILV estaban, entre otros, cargos de espionaje a favor de los EE.UU., o la cooperación con la CIA (Pérez, Robinson 1983; Rodríguez 1979; Pereira 1981). Mientras que estas acusaciones se mantienen sólo en el ámbito de la conjetura, bien documentados parecen ejemplos de apoyo a los intereses de las empresas estadounidenses que pretendían operar en las zonas habitadas por los indígenas que estaban bajo la influencia o "bajo la protección" del ILV (Hvalkof, Aaby 1981). Eso sucedió en el caso de los Huaorani.

En 1956, a las orillas del río Curaray, cinco misioneros norteamericanos protestantes decidieron de tratar de establecer contacto con los Huaorani,

7 El ILV en América del Sur trabajó entre más de cien grupos indígenas (Cabrera Becerra 2013). Véase también por ejemplo: http://www.peru.sil.org/es/sobre_sil_peru/historia

8 Por ejemplo, Stoll escribe: „La pareja de ILV viven lejos río abajo y parecen estar haciendo todo lo posible para ayudar a los guahibo defenderse" (Stoll 1981b: 68).

9 La mayoría de los misioneros tenía antecedentes sociales en los círculos evangélicos conservadores en el Centro-Oeste y el Sur de los Estados Unidos.
La actividad misionera de unas misiones de fe entre los grupos indígenas de la región amazónica y los intereses políticos de los gobiernos latinoamericanos Magdalena Krysińska-Kałużna 
Dossier América Latina: política y religión el grupo que en ese tiempo rechazaba contactos pacíficos con la sociedad nacional y con otros grupos indígenas. Sin embargo, los cinco temerarios pierden la vida durante este acontecimiento. Dos años mas tarde, los misioneros del ILV fundan una misión en el territorio Huaorani a orillas del Rio Tihueno. Lo hacen hermana y esposa de los hombres que murieron en el Curaray - Raquel Saint y Elizabeth Elliot.

Como en otros países, también en Ecuador, el ILV en los 50 firmó el contrato con el gobierno para educar a los indígenas. Luego el Instituto recibió también el permiso para establecer el "protectorado" para los recién contactados Huaorani en torno de su misión en Tihueno. En estas circumstancias, gran parte del grupo se movió y asentó en el relativamente pequeño territorio de Protectorado - solo bajo la influencia del ILV. ${ }^{10}$ Los misioneros, disponiendo de una base económica bastante rica, hacían vuelos sobre el territorio Huaorani comunicándose con los indígenas en la lengua huao. "Después llegaron las avionetas con los parlantes y la voz de Oncaye [una mujer Huaorani capturada en 1964 - MKK]; les enseñábamos las lanzas, pero esa voz nos invitaba a ir a Tihueno - cuenta Dabo, un guerrero - Nos han llamado muchas veces por el parlante en la selva para que no nos dejáremos coger por el padre, teníamos que ir a Tihueno. Nos repetían jvamos a Tihueno!” (Cabodevilla 1999: 390).

Hasta la expulsión del ILV del Ecuador en 1982, la educación de los Huaorani fue de la responsabilidad exclusiva de los misioneros. Son ellos que controlan todos aspectos de la vida del grupo. "Es imposible hablar de una sociedad huaorani posterior al contacto sin referirse a las actividades del ILV" (Rival 1996: 19; véase también: ibídem: 18-24). Cuando, en 1970, las primeras compañías petroleras entran a las tierras de los Huaorani, los misioneros no reaccionan. En 1974, Texaco, una de las mayores empresas de extracción de petróleo allí, sigue hacia dentro del territorio de los Huaorani. El ILV, usando los helicópteros pertenecientes a las compañías petroleras, realiza la segunda migración. Echan los machetes, las radios "por los cuales los Huaorani convertidos fueron capaz de hablar con sus hermanos malvados que todavía permanecieron profundo en el bosque. La mayoría de los otros Huaorani fue atraída a 600 kilómetros al oeste, al Protectorado. Desde entonces, su tierra fue robada y la cultura - destruida" (Rival, Lewis 1990). Bajo la influencia directa de los misioneros protestantes se encontró unos ochenta por ciento de los Huaorani. En 1979, se construyó la „vía Auca” ${ }^{11}$ para la producción petrolera que luego da entrada para la colonización.

10 „En tales condiciones similares de la frontera, abuelos de los misioneros estadounidenses habían pacificado el Oeste Americano y se colocando los "indios" en las reservas. Ahora sus nietos en el servicio del mismo Dios del siglo XIX propusieron reservas para los Shuar y Aucas [Huaorani - MKK]. Imagínese una "reserva" nativa ecuatoriana, una entidad jurídica, administrada realmente por los misioneros del ILV; cien años después, las cosas siguen siendo las mismas" (Robinson 1981: 47).

${ }^{11}$ Los Huaorani fueron conocidos como Aucas, una palabra en lengua quichua que significa „salvaje”. 
En 1991, tuve la posibilidad de observar la situación de los Huaorani durante el estudio de reconocimiento ${ }^{12}$ llevado a cabo por el grupo de investigadores del Instituto de Etnología y Antropología Cultural de la Universidad Adam Mickiewicz, en el cual participé. Observaciones realizadas durante este estudio indicaron una gran influencia de los misioneros protestantes también en una parte del grupo Huaorani que estaba fuera de relaciones directas con los misioneros protestantes. En una de las aldeas, habitada por más de 60 personas, el único que hablaba castellano fue un maestro Huaorani educado por los misioneros protestantes. Él se ocupaba de enseñanza pero también de la actividad proselítica, distribuyendo las grabaciones de fragmentos del Viejo Testamento y otros textos preparados por Raquel Saint en el Protectorado. Huaorani poseían las grabadoras de manivela proporcionadas por los misioneros. Su contacto con el mundo exterior fue mediado por el maestro o por los pilotos que llegaban a la aldea con los turistas. Uno de ellos (y pienso que el único que hablaba huao) fue hijo de Dayuma, la primera mujer Huaorani que mantuvo contacto con los misioneros y quien les ayudaba por muchos años en su trabajo de evangelización. Entonces los más importantes agentes de contacto tenían "sus agentes" también en la comunidad con la cual no tenían contacto directo y diario. ${ }^{13}$

Las buenas relaciones con los misioneros significaban para los indígenas las buenas relaciones con los que poseían las mercancías que necesitaban y el acceso a los cuidados médicos. Aceptar la ayuda, sin embargo, estaba atado de ganga. En el paquete era una visión del mundo que los misioneros querían pasar a los Huaorani y la capacidad de manipular las decisiones de los indígenas que no conocían las reglas del mundo con el cual apenas entraron en las relaciones.

El presidente de la compañía Maxus, William Hutton, era miembro de la misma iglesia que Raquel Saint. El acuerdo con los protestantes daba control a Maxus sobre lo que hacían los Huaorani. La compañía participaba en la educación y la educación para la salud de los Huaorani (Avirgan, Walker 1993). Tanto el ILV como la misma Raquel Saint (que finalmente se retiró del Instituto) negaban vínculos con el capital norteamericano que invirtió en la producción de petróleo. Como escribe Miguel Angel Cabodevilla, “todavía hoy falta por investigar sin detención este meridaje" (1999: 391), pero no hay duda de que las acciones de los misioneros estaban en relación con el gobierno de Ecuador y las compañías petroleras.

En 1993, se filmó en Toñampare (en el Protectorado) la ceremonia de inclusión de los Huaorani a la administración del Parque Nacional Yasuní (que

${ }^{12}$ El objetivo del estudio fue identificar los cambios en la parte del grupo Huaorani en varios aspectos de su vida sociocultural, tales por ejemplo como el estado de salud, economía o el contacto con el mundo exterior.

${ }^{13}$ Véase, por ejemplo, Mariusz Kairski, Iwona Stoińska, Informe sobre la situación de la cultura Waorani (el reporte preparado para CEDIME).
La actividad misionera de unas misiones de fe entre los grupos indígenas de la región amazónica y los intereses políticos de los gobiernos latinoamericanos Magdalena Krysińska-Kałużna 
Dossier América Latina: política y religión es la tierra tradicional de este grupo). Unos meses antes, los Huaorani o, mejor dicho, algunos de sus representantes, firmaron un convenio con Maxus, aceptando su presencia y la explotación de sus tierras por la empresa. Durante la ceremonia, la hija del presidente de Ecuador, Alicia Durán Ballén, quitó sus aretes de oro, las entregó a la madre de un representante de la organización Huaorani y dijó en inglés: “¿Crees que fue un buen reemplazo?”. Marcos Witznitzer, el consejero político de la embajada de Estados Unidos dijo: "Usando el mismo método hace tiempo ganamos Manhattan" (Avirgan, Walker 1993; cf. también: Krysinska-Kałużna 2012).

En el proceso de extracción del petróleo se destruyeron más de 20 millones de acres de tierra. Se contaminó agua y aire con 40.000 pies cúbicos de gas por día. Junto con las actividades de tala, construcción de oleoductos y carreteras, aparecieron colonos y desaparecieron los animales. Entre 1971 y 1991, Texaco, para ahorrar dinero echó desechos tóxicos (20 mil millones de galones de residuos tóxicos) directamente a los ríos y cabeceras de la selva, ignorando cualquier estándar. El gobierno, para permitir que la empresa minera Maxus - una de las empresas de extracción de petróleo que operaba en el territorio Huaorani - trabaje en un área específica, cambió los límites de un parque nacional (habitado por los Huaorani, también los grupos aislado). Aunque la Corte Constitucional declaró eso como ilegal, el gobierno ecuatoriano hizo nada para eliminar Maxus de la zona del parque. Hubo militarización de la región, apareció la prostitución, las enfermedades venéreas, el alcoholismo y la violencia. La destrucción del medio ambiente fue acompañada por la pobreza, la desnutrición y las enfermedades no sólo entre los Huaorani, pero entre unos 200.000 indígenas amazónicos del Ecuador (Krysińska-Kałużna 2000; Krysińska-Kałużna 2012).

\section{Conclusiones}

Las misiones de fe norteamericanas estaban relacionadas con grupos relativamente autónomos. "Las iglesias protestantes rechazaban la idea de evangelizar un continente ya cristianizado” (Tilkin Gallois., Benzi Grupioni 1995: 10, cf. también: Gonzales 1989). Gallois y Grupioni citan los folletos de la MNT para el reclutamiento de nuevos misioneros: "Una de las condiciones para la aceptación de los misioneros de la MNT, así como la terminación satisfactoria de nuestra formación es no ser miembro de iglesias cuyos nombres se añaden al Consejo Mundial de Iglesias o de sus afiliados " (What is the NTM, s/d, en: Tilkin Gallois, Benzi Grupioni 1995: 12). Según los autores, una de las razones es que el Consejo Mundial de Iglesias apoya ecumenismo y predica el mismo concepto básico de la igualdad entre los hombres. La aparición de misiones de fe está relacionada a la teología "dualista" que separa el "orden de Dios" de "trastorno humano." "El conflicto constante entre estos dos órdenes se actualiza tanto en términos de macro-política (que aplican el tipo de oposiciones 
capitalismo/socialismo, en la Guerra Fría) cuando el nivel de la micro-fundamentalismo institucional e individual" (id.: 13). No podemos presumir sin evidencias fuertes que el propósito de los misioneros era la cooperación con las empresas estadounidenses y el apoyo para ellas, la creación de una "santa alianza entre la cruz y el capital" o la búsqueda de información de utilidad para las agencias estadounidenses, como quieren unos críticos. Sin embargo, parece que el fin de evangelizar a los paganos dio los mismos resultados. Los misioneros, buscando la manera de cambiar la vida de los indígenas, los sacaban de los caminos de grandes empresas, agricultores, compañías petroleras y políticos quienes necesitaban terra nullius para sus proyectos.

Miguel Ángel Cabodevilla dice que las causas de los procesos que pasaban en el territorio Huaorani eran "mucho más complejas y reales que podríamos reasumir en: el interés del ILV por captar la totalidad de los grupos huaorani; la decisión de petroleros-ejército-Gobierno por explorar el sur del Napo; los intentos de la misión capuchina entre los grupos huaorani del este; al final, los propios intereses huaorani para encontrar a sus parientes, obtener parejas suficientes, terminar las guerras internas, etc.: todo ello contribuyó y, en cierto momento, aceleró la reducción del pueblo huao" (Cabodevilla 1999: 389). En el caso de los Aché, la situación era igualmente compleja. Las familias de los indígenas eran divididas y, además, los grupos que vivían sin contacto con la sociedad nacional estaban en la guerra entre ellos. Eso motivaba a los Aché para establecer el contacto pacífico con el "mundo exterior" y para la cooperación con los misioneros. En ambos casos, tanto de los Aché como de los Huaorani, los gobiernos habrían podido - teóricamente - basarse únicamente en el ejército (que de todos modos estaba involucrado en estos procesos) para controlar los territorios indígenas. Los misioneros iban a ser la solución "menos mala".

David Stoll dice que, según su conocimiento, ninguno de los misioneros del ILV ha dirigido una invasión a la tierra indígena (Stoll 1981b: 168). ${ }^{14}$ Pero debemos recordar que los misioneros, decidiéndose asumir el papel de los agentes de contacto, aceptaron, o debieron aceptar, la responsabilidad por el destino de los indígenas. Y por eso, a pesar de sus posibles buenas intenciones, no se puede no conectar sus acciones con la pérdida de la tierra por los Aché y los Huaorani, lo cual fue el objetivo de los gobiernos que empleaban a los misioneros o de las empresas petroleras que operaban en la región.

Destinada aculturación de ambos grupos indígenas fue otro cambio muy importante presumido por los gobiernos y realizado conscientemente por las instituciones misioneras. Algunos de los misioneros no aceptaban las iniciati-

${ }^{14}$ Hay que mencionar que David Stoll no siempre es tan suave en la evaluación de las acciones de los misioneros del ILV. Miguel Ángel Cabodevilla cita Stoll: "Para pacificar a los próximos dos grupos, las misioneras los desarraigaron de su tierra y convirtieron Tihueno en un campo de refugiados, destruyendo un breve experimento de cristianismo primitivo. La reubicación se modeló en la convergencia de los planes de corporaciones, gobiernos y un ILV dedicado al servicio cristiano" (Stoll 1985 en: Cabodevilla 1999: 388).
La actividad misionera de unas misiones de fe entre los grupos indígenas de la región amazónica y los intereses políticos de los gobiernos latinoamericanos Magdalena Krysińska-Kałużna 
Dossier América Latina: política y religión vas de sus correligionarios, pero prevaleció la actitud conformista que dejó seguir a las misiones el objetivo principal, la conversión de los indígenas a toda costa (Cabodevilla 1999: 383-399; cf. Lewis 1988: 114).

Pienso que los dos elementos más críticos en el proceso de establecimiento del contacto con los grupos aislados son las actividades de los agentes del contacto y el respeto al derecho a la tierra que casi siempre es interdependiente (Krysińska-Kałużna 2012). La actividad de los ILV y MNT llevada a cabo entre - respectivamente - los Huaorani y los Aché, dio lugar a cambios en la esfera de las creencias, costumbres, sistemas de valores y la estructura social, influyó su vida en cada aspecto, lo que hizo muy difícil o casi imposible la reproducción de la cultura tradicional en algunas comunidades Huaorani y Aché. Los misioneros, como agentes de contacto, aprovecharon su estatus y ventajas que éste les daba. Aprovecharon, sobre todo, la autorización de los gobiernos para iniciar proselitismo en asentamientos indígenas. Además, los gobiernos de los países en los que vivían los grupos recién contactados permitieron que el proceso del contacto cultural fuera llevado a cabo en manera que amenazaba la supervivencia cultural y física de los indígenas. La política de contactar a los grupos aislados, sedentarizarlos y convertirlos serviría muy bien a los planes y objetivos de las autoridades de apertura de la selva para los intereses mineros y madereros. Mientras los indígenas dejaban su forma de vida, su tierra fue vendida u ocupada - de todos modos, perdían el control sobre sus territorios. La pacificación de los indígenas estaba en el interés de los gobiernos también porque podían esperar una rápida integración de los pueblos indígenas a las sociedades nacionales, sin tener que pagar los costos de estas operaciones.

La violencia simbólica conduce a cambios culturales en una forma directa, la violencia física - dependiendo de la gravedad - puede destruir la base material que sirve para reproducir la cultura. La violencia es inherente a la actividad de un representante de la cultura dominante.

Las campañas de misionalizaciones forzosas servirían para asimilar las culturas indígenas a la cultura dominante. Los misioneros usaron el poder en la forma que podemos analizar con la visión tridimensional de Steven Lukes. En el caso de los Aché, usaron no sólo la violencia simbólica, sino también la violencia física en forma de cacerías humanas. Bourdieu menciona que en la situación de la violencia simbólica, las condiciones en que se forman patrones de percepción y de la disposición forzan a los dominados a adoptar el punto de vista de los grupos dominantes. En este contexto, podemos analizar las posturas de unos señuelos, como Lorenzo, o la firma del convenio con Maxus por unos Huaorani. La educación de los indígenas también fue una herramienta de dominación, como la reproducción y el cambio de los sistemas sociales son - según Bourdieu - conectados en una forma especial con las instituciones educativas y el proceso de aprendizaje. Los cambios más profundos tienen lugar cuando se relacionan al habitus porque es una operación hecha en el mundo simbólico del hombre, sus formas de entender, categorizar y nombrar la realidad. 
Los agentes de contacto prácticamente no estaban controlados por el Estado pero explotados por ellos para sus propios fines y podían actuar de acuerdo con sus propios objetivos y motivaciones, independientemente si eso causaba la desintegración de las culturas con las que interactuaban o no. Y ese es un rasgo característico de los agentes del contacto y su forma de actuar. En la Amazonía y Gran Chaco viven cerca de cien grupos aislados. Hoy en día, su supervivencia depende en gran medida de si van a ser capaces de resistir a los grupos de interés que buscan fuentes de beneficios rápidos en tierras indígenas. Esto requiere procedimientos que permitan la prevención de los efectos del contacto cultural que amenazan a la supervivencia étnica y cultural de estos grupos.

\author{
La actividad misionera \\ de unas misiones de fe \\ entre los grupos indígenas \\ de la región amazónica y los \\ intereses políticos de los \\ gobiernos latinoamericanos \\ Magdalena Krysińska-Kałużna
}

\section{Bibliografía}

Avirgan T. (1993), Ch. Walker, Trinkets and Beads, película documental, Sunnyside Productions.

Bottasso J. (ed.) (1990), Misioneros y antropólogos, frente a frente, Quito.

Bourdieu P., Passeron J.-C. (1990), Reprodukcja. Elementy teorii systemu nauczania, PWN, Warszawa.

Bourdieu P., Wacquant L. J. D. (2001), Zaproszenie do socjologii refleksyjnej, Oficyna Naukowa, Warszawa.

Cabodevilla M. Á. (1999), Los Huaorani en la historia de los pueblos del Oriente, Cicame, Quito.

Cabrera Becerra G., Apuntes para una historia de los protestantes y su actuación entre los pueblos makú del Alto Río Negro-Vaupés, en: Upper Rio Negro. Cultural And Linguistic Interaction In Northwestern Amazonia, 2013, disponible en: https://www.researchgate. net/publication/296696787_Apuntes_para_una_historia_de_los_protestantes_y_su_ actuacion_entre_los_pueblos_Maku_del_Alto_Rio_Negro_-Vaupes, fecha de consulta: 14.03.2016.

Comisión Verdad y Justicia, Dictadura de Stroessner y Pueblos Indígenas. Informe final, Paraguay 2008, disponible en: http://www.staff.uni-marburg.de/ muenzel/arhek/2008\%20 Informe\%20final.pdf, fecha de consulta: 14.03.2016.

Fenelon J. (1998), Culturcide, Resistance and Survival of the Lakota (Sioux Nation), manuscrito.

Ecuador's Black Plague (2004), disponible en: wwww.witness.org, fecha de consulta: 15.01.2008.

Harder Horst R. D. (2000), Political advocacy and religious allegiance: catholic missions and indigenous resistance in Paraguay (1982-1992). Ponencia presentada en la reunión del 2000 de la Latin American Studies Association, Miami, Florida.

Harder Horst R. D. (2011), El régimen de Stoessner y la resistencia indígena, Centro de Estudios Antropológicos en la Universidad Católica, Asunción Paraguay, disponible en: http://www. portalguarani.com/2719_rene_d_harder_horst/20410_el_regimen_de_stroessner_y_la_ resistencia_indigena_por_rene_d_harder_horst.html, fecha de consulta: 14.03.2016. 
Dossier América Latina: política y religión
Hvalkof S., Aaby P. (1981), No Tobacco, No Hallelujah, en: Is God an American?, S. Hvalkof, P. Aaby (eds.), IWGIA y Survival International, Copenhagen.

Hvalkof S., Aaby P. (eds.) (1981), Is God an American?, IWGIA y Survival International, Copenhagen.

Jacyno M. (1997), Iluzje codzienności. O teorii socjologicznej Pierre’a Bourdieu, Wydawnictwo IFiS PAN, Warszawa.

Krysińska-Kałużna M. (2000), Indianie i misje. Misjonarze w procesie kontaktu i zmiany kulturowej w Amazonii, „Lud”, t. LXXXIV, pp. 11-37.

Krysińska-Kałużna M. (2012), Yamashta czyli Ten Który Prawie Umarł. Proces kontaktu a przetrwanie kultur indiańskich w Amazonii, Oficyna Naukowa, Warszawa.

Lewis N. (1988), The Missionaries. God against the Indians, Vintage, London.

Mesa Memoria Histórica y Archivos de la Represión 1954-1989, disponible en: http:// mesamemoriahistorica.org.py/wp-content/uploads/2014/10/Info-in-extenso-investigaci\%C3\%B3n11.pdf, fecha de consulta: 14.03.2016.

Mucha J. (1999), Dominacja kulturowa i reakcje na nia, en: Kultura dominujaca jako kultura obca. Mniejszości kulturowe a grupa dominująca, J. Mucha (red. nauk.), Oficyna Naukowa, Warszawa.

Münzel M. (2008a), Los indígenas Aché: Genocidio en Paraguay, en: Los Aché del Paraguay: Discusión de un Genocidio, A. Parellada, M. de L. Beldi de Alcántara (eds.), IWGIA, Copenhague.

Münzel Mark (2008b), Los Aché: El genocidio continúa en Paraguay, en: Los Aché del Paraguay: Discusión de un Genocidio, A. Parellada, M. de L. Beldi de Alcántara (eds.), IWGIA, Copenhague.

Oil Companies Threaten Indian Communities and Amazon, 1991, disponible en: abyayala. nativeweb.org/ecuador/amazon/oil/amazon1.html, fecha de consulta: 14.03.2016.

Parellada A., Beldi de Alcántara M. de L. (eds.) (2008), Los Aché del Paraguay: Discusión de un Genocidio, IWGIA, Copenhague.

Perez G., Robinson S. (1983), La misión detrás la misión. The mission behind the Mission (Edición bilingüe), COPEC/CECOPE Y CADAL, México.

Rival L., Lewis D. (1990), Still life in oil, „BBC Wildlife”, London, December, pp. 834-836.

Robinson S. (1981), Fulfilling the Mission: North American Evangelism in Ecuador, en: Is God an American?, Hvalkof Søren, Aaby Peter (eds.), IWGIA y Survival International, Copenhagen.

Rodriguez N. J. (1979), Apuntes para la interpretación de una transnacional misionera: el caso del Instituto Lingüístico de Verano (ILV), en: Imperialismo y descolonización. Imperio, „desarrollo" y ciencias sociales, t.1, CIESAS-INI-SEP, México.

Said E. W. (1991), Orientalizm, Państwowy Instytut Wydawniczy, Warszawa.

Santa Cruz M. C. (2012), Consultoría de investigación sobre diversidad sociocultural en Paraguay, Secretaría Nacional de Cultura Centro de Investigaciones en Filosofía y Ciencias Humanas (CIF), Paraguay.

Servín J. A. (2008), Stroessner, su dictadura y los impactos en el pueblo Aché, en: Los Aché del Paraguay: Discusión de un Genocidio, A. Parellada, M. de L. Beldi de Alcántara (eds.), IWGIA, Copenhague. 
Stoll David (1993), Introduction: Rethinking Protestantism in Latin America, en: Rethinking Protestantism in Latin America, V. Garrard-Burnett, D. Stoll (eds.), Temple University Press, Philadelphia.

Stoll David (1981a), Words Can Be Used In So Many Ways, en: Is God an American?, S. Hvalkof, P. Aaby (eds.), IWGIA y Survival International, Copenhagen.

Stoll David (1981b), Higher Power: Wycliffe's Colombian Advance, en: Is God an American?, S. Hvalkof, P. Aaby (eds.), IWGIA y Survival International, Copenhagen.

Survival International, Tribu de América del Sur lleva a los tribunales una demanda por genocidio histórico, 1 julio 2014, disponible en: http://www.survival.es/noticias/10324, fecha de consulta: 14.03.2016.

Tilkin Gallois D., Benzi Grupioni L. D. (1995), O Índio na Missão Novas Tribos, mecanografiado.

Tucker R. A. (1995), Sławni i nieznani. Niezwykłe postaci $z$ historii misji, Oficyna Wydawnicza „Vocatio”, Warszawa.

Wacquant L. J. D. (2001), Wprowadzenie, P. Bourdieu, L. J. D. Wacquant, Zaproszenie do socjologii refleksyjnej, Oficyna Naukowa, Warszawa.

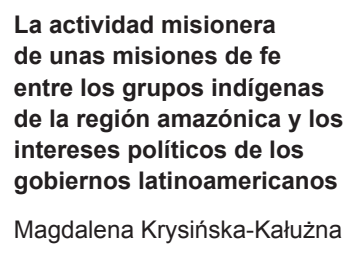

La actividad misionera de unas misiones de fe entre los grupos indígenas de la región amazónica y los

Magdalena Krysińska-Kałużna 